\title{
Critical Overview: \\ Gender and \\ Tentative Language
}

No. 1, 16-26

(C) The Journal Editors 2017

Reprints and permissions: https://tidsskrift.dk/lev

DOI: 10.7146/lev.v0i1.96778

Recommendation: Michaela Hejná

(misa.hejna@cc.au.dk)

English Linguistics 3

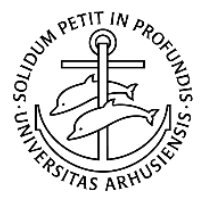

Kristina Sommerlund

\begin{abstract}
This article examines the relationship between tentative language and gender. In 1975, linguist Robin Lakoff hypothesized that women tended to use unassertive speech forms because of their inferior and powerless position in society. On the basis of these assertions by Lakoff, this article seeks to create a critical overview of various studies that have consulted the issue of women's use of tentative language. Specifically, the article is concerned with hedging, investigating whether women have been found to use this linguistic device more often than men. The article consults five different studies on gender and tentative language, discusses the strengths and weaknesses of these studies, and finally, discusses whether the studies overall show any significant differences in the way men and women use unassertive speech forms.
\end{abstract}

Keywords: sociolinguistics, gender differences, women, tentative language, hedging

Corresponding author: Kristina Sommerlund (kristina.sommerlund@ post.au.dk)

Department of English, Aarhus University 


\section{Introduction}

In 1975 linguist Robin Lakoff published the book Language and Women's Place, which became a significant source of influence for various future studies concerning the relationship between gender and language. In the book she seeks to demonstrate the ways in which women are undermined in society both through the language used by them and through the language used about them. Her hypotheses about the general unassertiveness and powerlessness of what she refers to as 'women's language' has invited academics from various disciplines to investigate further in this area. According to Lakoff, one characteristic of 'women's language' is the use of hedges, which are words or phrases that are typically used as a mitigating device in conversation. Taking Lakoff's work as a starting point, the focus of this article is then on the relationship between gender and unassertive language, and in particular the relations between gender and the use of hedges. The article will address the following research question: Do women use hedges and other tentative devices more frequently than men? The article will focus on a range of studies that have addressed this particular issue.

\section{Tentative Language}

To get an overview of Lakoff's work, this first section will deal with the characteristics of what she refers to as 'women's language'. Lakoff's main point of view is that inequality between genders is reflected in the way they talk. She argues that women are exposed to linguistic discrimination "in the way they are taught to use language, and in the way the general language use treats them" $(1975,4)$. According to Lakoff, women are 'kept in place' in society by being taught to talk like 'little ladies' they have to be polite and not 'talk rough' like boys, and as a result thereof they acquire insecure and unassertive speech forms $(1975,5)$. Lakoff points to nine forms of tentative language that women tend to use - some of them will be summarized here. Firstly, tag questions (e.g., The food is delicious, isn't it?) constitute a type of tentative language, as the addition of a tag to a declarative suggests that the speaker wants confirmation of his or her statement. Secondly, intensifiers, so in particular (e.g., He is so handsome) indicates that the speaker seeks to dampen a statement, using it as a way of not sounding too assertive. Other features that Lakoff points to include hypercorrect grammar (that women are more careful and correct in their speech than men), superpolite forms, namely that "women are the repositories of tact and know the right things to say to other people, while men carelessly blurt out whatever they are thinking" $(1975,55)$, and use of empty adjectives (divine, charming, cute etc.) The common link between the abovementioned speech forms is that they can all be used as a way of downplaying a statement, making the speaker seem less direct and more uncertain of his or her utterances - a characteristic that Lakoff assigns to women (1975, 52-55). 
According to Lakoff, hedges constitute a part of 'women's language' as well. Hedges are within the field of pragmatics linguistic forms, which serve to mitigate a statement. Typical hedges are you know, sort of, kind of, I think and perhaps. Hedges are very common in everyday conversation, and though they typically express uncertainty, this is not always the case, which will be discussed later on.

\section{Studies on Hedging and Gender}

When Lakoff published her work in 1975, the concept of gender was treated as a binary opposition: there are men, who are of the male sex, and there are women, who are of the female sex. However, much has changed since then, and today it is commonly held that the terms 'sex' and 'gender' are two distinct things. Sex is a biological term, which categorizes individuals as being either male or female, while gender is a social construct, which covers the degree of masculinity or femininity an individual identifies with. Gender is thus a much more fluid term than sex, and this can be challenging for studies on gender and language. The challenge lies in the fact that it is more difficult to measure gender as either one or the other (male or female) when conducting a study. Female speakers do not necessarily view themselves as one hundred per cent feminine and vice versa. It is no longer possible to treat gender as a binary - instead "gender is conceptualised as plural, with a range of femininities and masculinities available to speakers at any point in time." (Coates 2013, 4). However, most studies prefer the term 'gender' over 'sex', as the way individuals choose to speak is mostly a function of gender, not sex - and statistically speaking, sex corresponds to gender in most cases (Eckert 1989, 213). To return to hedging, and how men and women use this linguistic device, the next section will create an overview of various studies that have consulted this particular issue.

Lakoff was the first to address the relationship between hedging and women. She points out three different uses of hedges - hedges that express a genuine uncertainty (e.g. Her hair is sort of long, which indicates that her hair is neither very long or very short), hedges that reduce the unkindness of a statement, serving as an act of politeness (e.g. He acted kind of strange), and finally hedges that occur, even though the speaker is certain of the truth of the assertion (e.g. He sort of gave me the present) (Lakoff 1975, 54). Lakoff interprets the use of the last-mentioned hedges as a sign of insecurity, and claims that women use this type of hedge more frequently than men: "my impression is that women do it more, precisely because they are socialized to believe that asserting themselves strongly isn't nice or ladylike, or even feminine" $(1975,54)$. Her suggestion is that women use these tentative and unassertive hedges as a result of their powerless and inferior position in society. However, Lakoff's work seems to be somewhat unreliable, as her claims are mainly based on 'impressions' (as she also mentions herself in the quotation above) and more general observations, which she has gathered by introspection and by use of the media (Lakoff 1975, 4). She bases her work 
merely on speculations, and while many have criticized her book for its general lack of empirical evidence, the publication of it prompted several linguists to test her hypotheses (Coates 2013, 5).

One linguist who has certainly put Lakoff's hypotheses to test is Janet Holmes. Her work includes several studies on the use of hedges in relation to men and women. One of her studies investigates the use of a few pragmatic particles, namely you know, sort of/kind of and of course particles that she claims function as "conversational lubricants in interaction" (Holmes 1987, 61) that is, filler words, which a speaker can use to buy time when formulating an utterance. Holmes further suggests that these pragmatic particles, or hedges, may have other functions as well. She states that hedges such as you know, I think and sort of can express two types of meaning: "modal meaning expressing the extent of the speaker's certainty, and affective (or social) meaning, expressing the speaker's attitude to the addressee in the interaction" (Holmes 1987, 61). A hedge such as I think clearly belongs to the first category, as it refers to the speaker, while the hedge you know expresses affective meaning, as it addresses the listener.

Holmes' dependent variable in this study was the use of the two hedging devices you know and sort of, as well as the use of the emphatic of course. Her independent variables were gender (men vs. women, treated as a binary variable) and geographical location/dialect (Britain vs. New Zealand). The study was based on data from a corpus consisting of 50,000 words with equal quantities of male and female speech. The speakers ranged from age 18-65, and were primarily of middle class origin. Holmes took notice of the different functions hedges such as you know could have. She divided it into two categories: instances where the use of you know expressed confidence, and instances where it expressed uncertainty. When you know is used confidently, the speaker tries to make sure that the listener knows what he or she is talking about. Example:

I'm the boss around here you know [Young woman joking to neighbour in presence of flat mates] (Holmes 1987, 63)

Used this way, you know is not a hedging device, but rather an intensifier or booster (Holmes 1987, 63). In the example, the speaker is addressing her audience directly, and thus uses you know as a device for engaging her audience in the conversation, making it a confident speech form rather than an insecure one.

When you know is used unassertively, it serves to mitigate the utterance, often in connection with other mitigating devices. Example:

... and it was quite // well it was all very embarrassing you know [Young woman to close friends] (Holmes 1987, 63) 
In this example, the speaker is clearly looking for words, and generally has a difficulty with expressing herself confidently to her audience. Holmes calls this an "addressee-oriented uncertainty" $(1987,63)$.

Holmes results showed that there were in fact no significant differences in the distribution of you know used by men and women. There were nearly equal instances of you know in men's and women's speech in both New Zealand English and British English. However, the results showed that there was a significant difference in the way men and women used you know. While men used it mostly to express uncertainty, women tended to use it confidently - results, which directly contradict Lakoff's suggestion that women are more tentative in their language than men (Holmes 1987, 64). Holmes found similar results for the hedge sort of, where the results showed that men used sort of more frequently than women - overall, the hedge occurred 62 times in male speech, while it only occurred 35 times in female speech (Holmes 1987, 66). The results further showed that sort of was more common among British speakers than New Zealand speakers, so it seems that dialect is an important factor as well when investigating the use of hedges. Lakoff's hypotheses are based on American English, and the use of hedges may be different in this dialect, which Holmes comments on as well: “Lakoff's claims about 'women's language' may have to be relabelled 'American women's language'" $(1987,75)$. Holmes' results refutes Lakoff's hypotheses on two levels - firstly, women did not use hedges more frequently than men, and secondly, women's use of hedges proved not to be a sign of weakness or tentativeness, instead women used hedges mainly as an affective and inclusive device.

Crosby and Nyquist tested Lakoff's hypotheses in an American context. They did three studies that tested some of the features of 'women's language', namely empty adjectives, tag questions, hedges and the intensifier so. They assigned these features to what they named 'the female register' (a relabelling of Lakoff's term 'women's language'), and in line with Lakoff's claims, they predicted that characteristics of the female register would be more prominent in women's speech. The first study tested 16 female and 16 male undergraduates from Boston University. They were tested in a 3minute conversation on an assigned topic with a person of the same sex. The amount of 'female register' in the speech of the subjects was then analysed afterwards. The results of this first study showed that women did in fact use characteristics of the female register more often than men (Crosby and Nyquist 1977, 316). To create a less controlled study, Crosby and Nyquist tested 107 males and 90 females asking for help at an information booth. In this study they tested both same-sex interactions and mixed-sexed interactions, and found that male-male interactions contained the least amount of female register. This study did not however show a significant difference in the overall use of female register for male and female speakers. They suggest that this study was flawed, as it was difficult to detect any variation in such short interactions, and in addition, the information-seeking 
process is highly ritualized, which might have diminished the differences between the sexes (Crosby and Nyquist 1977, 320).

Lastly they conducted a study, which aimed to find out whether status had any influence on the use of the female register. Lakoff asserts that women of higher status (female academics), refrains from using 'women's language', and that academia in general is "a more egalitarian society than most, in terms of sex roles and expectations" (1975, 57), and Crosby and Nyquist tested this hypothesis in their third study. The subjects in this study were police personnel from Connecticut and 45 female speakers and 45 male speakers. The conversations between the police personnel and the clients were coded by a research assistant. To investigate the effect of status on speech, they treated the status of the police personnel (clerk and officers) as an independent variable. However, they found that the clerk did not differ from the officers in amount of female register, which indicates that status has no significant influence on the use of tentative language. The overall results were similar to their first study, as they revealed that women used the female register more than men. In addition, they found that clients used the female register more than the police officers - results that could reflect the power relations between clients and officers (Crosby and Nyquist 1977, 319). Crosby and Nyquist's study does not directly deal with the use of hedges, but its results indicate that tentative language, including hedges, may be more frequently used by women than men in an American context.

20 years after Crosby and Nyquist's study John Dixon and Don Foster did a study on hedging and gender. Their study partially builds on Holmes' earlier studies, which, as illustrated earlier, showed a more nuanced picture of men's and women's use of hedges. Dixon and Foster tested subjects in a South-African context, and presented two hypotheses based on Holmes study. Firstly, they hypothesized that men would use hedges to express uncertainty more frequently than women. Secondly, they predicted that women would "employ hedges that serve socio-emotional functions more frequently than men" $(1997,92)$.

Moreover, Dixon and Foster were interested in the situation in which the hedges were uttered, and predicted that speakers of both sexes would use fewer hedges in a competitive than in a noncompetitive situation (1997, 92). Another independent variable was audience gender, as they examined whether gender of the listener affected men's and women's use of hedges. The study focused only on the hedges sort of and you know.

The subjects of the study were 50 male undergraduates and 54 female undergraduates. The experiment was controlled, in that the subjects were seated at a table, and then instructed to have conversations that lasted around 8 minutes - a casual conversation in the non-competitive situation and a debate-based conversation in the competitive situation. In the competitive situation they were told that they would be judged on their performances in the debate. The results of the study disconfirmed the first two hypotheses. Contrary to Holmes' findings, Dixon and Foster did not find any differences in the way men and women used the hedges sort of and you know. Their two initial 
hypotheses were thus refuted. Furthermore, there were no major differences in the quantity of hedges uttered by men and women, which, similarly to Holmes' results is inconsistent with Lakoff's claims. However, Dixon and Foster were able to confirm their third hypothesis, namely that both men and women were less likely to use hedges in a competitive situation, compared to a non-competitive one. This goes to show that the situation or social context of conversations does play a role in relation to hedging. Dixon and Fosters main conclusion is then that the investigation of hedges is complex: hedges can express various social functions, and the use of hedges in general may be more governed by social context than by the gender of the speaker $(1997,103)$.

As the studies consulted above illustrate, there are many factors to take into consideration when examining hedges and gender. Furthermore, none of the studies provide definite evidence for the existence of a 'women's language' - that women in fact use tentative language more than men. Because of the conflicting nature of research on the topic, researchers Leaper and Robnett recently did a meta-analysis of 29 studies on gender differences in the use of tentative language. A metaanalysis is a technique that analyses the statistical findings across studies that deal with similar issues, and it can reveal whether there are any statistically significant effects across these studies (Leaper and Robnett 2011, 130). The clear advantage of this meta-analysis is that it provides a broad overview of the various results of studies that have examined the relations between gender and tentative language. Across all these studies, there were a total of 3.502 participants, and a sample of that size may provide us with a more complete and clarifying view on the subject (Leaper and Robnett 2011, 129).

Leaper and Robnett focused on four forms of tentative language (as first formulated by Lakoff): expressions of uncertainty, hedges, tag questions and intensifiers. They further investigated six conversational aspects that could be of significance to the results of the various studies. The aspects they considered were: gender composition of the group or dyad, relationship among the conversational partners, student status of participants, group size, conversational activity and physical setting of the experiment (Leaper and Robnett 2011, 132). The meta-analysis supported Lakoff's hypothesis about women's use of tentative language to some degree. It showed that women tended to use the unassertive speech forms more frequently than men in some cases, but the results also revealed that "[f]or the vast majority of women and men in the sampled studies, there was much more overlap than difference in the use of tentative speech" (Leaper and Robnett 2011, 137). This suggests that tentative language is not solely a characteristic of 'women's language' but an integral part of both men's and women's speech. Leaper and Robnett conclude that men and women are more similar than different, and that the use of tentative language is highly context-dependent (Leaper and Robnett 2011, 139). 


\section{Discussion}

Based on some relevant points in Leaper and Robnett's analysis, this section will discuss the strengths and weaknesses of the studies described in the previous section.

All the studies agree on the fact that Lakoff's work is relatively uniform, and that she at times fails to acknowledge important factors. The common feature of the studies is that they all investigated Lakoff's claims with different independent variables. Holmes found no difference between men and women in the use of the hedges you know and sort of, but instead found that hedges can function in different ways. Holmes subjects were speakers from Britain and New Zealand, and it is important to note that the use of hedges may vary across dialects. This is confirmed through the findings of Crosby and Nyquist, as they tested subjects in an American context, and found evidence that supported Lakoff's claims. One of the weaknesses of Crosby and Nyquist's study however, is the relatively small sample size - in their first experiment, they tested only 32 subjects, who were all undergraduate students, and while that may be sufficient to show some general tendencies, it is not as convincing as Holmes study, which was based on a large corpus with speakers of all ages. Leaper and Robnett noted that studies which used undergraduates as participants found greater gender differences, than studies, which did not use college students as participants. This suggestion is in conflict with Lakoff's suggestion that academia is an egalitarian society in terms of gender roles $(1975,57)$. But Leaper and Robnett argues that life stages may play a role in relation to this, as it is highly plausible that younger adults will use more unassertive forms, because they are more self-conscious and concerned with identity than older individuals $(2011,138)$. This is apparent in the recent trend of using like as a hedge, as it is particularly popular among young people (Coates 2013, 88). Holmes study is thus advantageous as she tested subjects across different life stages.

Dixon and Fosters study was similar to Holmes' study, as it revealed no differences between men and women in terms of their use of hedges. Dixon and Foster tested South African undergraduates, and once again, it is possible that dialect is an important factor when investigating hedges. It seems that hedging in general is more widespread in USA and Britain, something which is supported by Holmes' study, as she found that British speakers used the hedges sort of and you know more frequently than New Zealand speakers. Dixon and Foster found that speakers used fewer hedges in competitive situations, which indicates that context of conversation is an important factor. Speakers will perhaps take on hedging in some situations (for example in casual conversations), and avoid it in other situations (for example in a job interview). Lakoff accounts for this possibility as well, when discussing the characteristics of 'women's language': "If you are a woman, it is more likely that you will speak this way than if you are a man, but that is not to say that I predict you do speak this way if you're a woman, or don't if you're a man. Further, you could speak this way to some extent; or could speak it under some circumstances, but not others" $(1975,57)$. Moreover, Leaper and Robnett found 
that gender differences in tentative speech were more marked in larger groups of people, when compared to dyadic conversations. People may be more eager to get their viewpoints across in group interactions, and this could result in larger gender differences. In dyadic conversations however, individuals may be more likely to treat each other as equals $(2011,138)$. Conversational context is thus an important factor to consider when assessing gender differences in hedging.

Another aspect to take into consideration is the time of the studies. Lakoff published her book in the 1970's, and it is safe to say that gender roles and society as a whole have changed since then. Some of Lakoff's assertions certainly seem rather archaic when related to modern society. For instance, Lakoff argues that "women have no sense of humor" $(1975,56)$ or that women are solely “identified in terms of the men she relates to (...) women are only 'John's wife' or 'Harry's girl friend"'(1975, 31). While this was probably true of Lakoff's time, it does not seem to be entirely true of western society today. Women have gained more independence since then, and are no longer perceived primarily as wives and mothers. Crosby and Nyquist released their study two years after Lakoff's book, and found support for her hypotheses. Dixon and Foster's study however, refuted Lakoff's hypotheses, and the fact that it was released 22 years later, in 1997, may be of importance. However, Leaper and Robnett found in their meta-analysis that publication year of the various studies did not play a role in relation to gender differences. They explain that this may be because tentative language "reflect[s] interpersonal sensitivity more than lack of assertiveness" (Leaper and Robnett 2011, 137).

Methodologically, Leaper and Robnett found that across all studies, length of observation had a significant effect on the outcome. Studies with longer observations (over 11 minutes) found larger gender differences (Leaper and Robnett 2011, 137). Crosby and Nyquist only observed conversations that lasted around 3 minutes - similarly, the conversations observed in Dixon and Fosters study only lasted around 8 minutes. This may not be sufficient to detect significant differences. Additionally, controlled settings may also interfere with the outcome, as participants can become increasingly aware of their speech. A controlled setting can both increase tentative language, perhaps because speakers become insecure or uncomfortable, or it can work the other way around, making the speakers overly careful in their speech. Conclusively, there are several factors that need to be considered when addressing the issue of tentative language and gender. Perhaps the most salient one is that hedging and 'tentative' language is not solely an expression of insecurity - it can function in various ways. 


\section{Conclusion}

Based on the studies consulted in this overview, it can partially be concluded that women do not use hedges or other mitigating devices more than men. This article found no convincing support for the existence of a 'women's language', namely that women are more unassertive than men in their speech forms. One study found that women were in fact more tentative in their language than men, while two other studies found no significant gender differences in terms of hedging. A meta-analysis found a small gender difference in tentative language, but overall concluded that men and women are perhaps not as different in their speech as Lakoff first asserted. General use of hedges turned out to be marked by various factors including dialect and situational context. Furthermore, it was found that hedges might not always function as markers of unassertiveness, as Lakoff suggested, but rather, hedges such as you know and sort of can be used as an inclusive device in conversation. It can thus be concluded that hedges are multifunctional, and that women may use certain speech forms more than men in some situations, but not in others. Because gender has become an increasingly complex matter over the years, there is certainly still room for further investigation on this issue. 


\section{References}

Coates, Jennifer. 2013. Women, Men and Language: A Sociolinguistic Account of Gender Differences in Language. Third Edition. New York: Routledge.

Crosby, Faye and Nyquist, Linda. 1977. "The Female Register: An Empirical Study of Lakoff's Hypotheses." Language in Society 6 (3): 313-322. doi:10.1017/S0047404500005030.

Dixon, John A. and Foster, Don H. 1997. "Gender and Hedging: From Sex Differences to Situated Practice.” Journal of Psycholinguistic Research 26 (1): 89-107. doi:10.1023/A:102506420547.

Eckert, Penelope. 1989. "The Whole Woman: Sex and Gender Differences in Variation.” In Sociolinguistics, A Reader and Coursebook, edited by Nikolas Coupland and Adam Jaworski, 212-28. New York: Palgrave.

Holmes, Janet. 1987. "Hedging, Fencing and Other Conversational Gambits: An Analysis of Gender Differences in New Zealand." Researchgate.net. https://www.researchgate.net/publication/246363637_Hedging_your_bets_and_sitting_on_the_f ence_Some_evidence_for_hedges_as_support_structures. (Accessed 22-05-2017).

Lakoff, Robin. 1975. Language and Woman's Place. New York: Harper and Row.

Leaper, Campbell and Robnett Rachael D. 2011. "Women Are More Likely Than Men to Use Tentative Language, Aren't They? A Meta-Analysis Testing for Gender Differences and Moderators." Psychology of Women Quarterly 35 (1): 129-142. doi:10.1177/0361684310392728. 